\title{
Outcome-based Dental Education and Identification of Practice Gaps; A Narrative Review
}

\author{
Sarah Ghafoor ${ }^{1}$ \\ Junaid Sarfraz Khan ${ }^{2}$
}

BDS, BSc, PhD

FCPS, FRCS, Dip. (Med. Edu), M. Med, PhD

Undergraduate dental education aims to provide the society with competent dental graduates that are able to serve in the community as independent practitioners. The rotational clinical training provided in our current dental settings do not fully prepare dental graduate for comprehensive dental care as the focus is more on subject areas rather than as a whole. Outcome-based dental education defines certain outcome-competencies that are essential part of dental curriculum and also provide a roadmap for curriculum developers regarding expectation from a beginner dental graduate. These competencies are based on knowledge, skill and attitudes that a beginner dentist is able to practice professionally and ethically. The review focuses on competence of dental graduates and discusses gaps that have been identified by the dental schools elsewhere that have led to valuable insights regarding readiness for comprehensive dental care in a beginner dentist. This information may direct dental policy makers and curriculum developers to focus their goals towards a dentist who is more trained in comprehensive dental care within undergraduate level or in immediate post-graduation level before exit into the community.

KEY WORDS: Dental, Fresh Graduate, Gap, Pratice, Identification, Outcome-based, Education

HOW TO CITE: Ghafoor S, Khan JS. Outcome-based dental education and identification of practice gaps; a narrative review. J Pak Dent Assoc 2019;28(1):41-46.

DOI: https://doi.org/10.25301/JPDA.281.41

Received: 07 September 2018, Accepted: 28 December 2018

\section{INTRODUCTION}

$\mathrm{T}$ he main focus of an undergraduate dental education program is to equip the community with competent dentists who are able to serve societal needs and improve population oral healthcare. ${ }^{1}$ Pakistan Medical and Dental Council (PM\&DC) is the national regulatory body that establishes minimum standards for education and licensure dentistry, and sets standards for the instructors in medical/dental colleges in Pakistan. In addition to basic medical sciences subjects, the initial two years of Bachelor of Dental Surgery (BDS) in Pakistan are devoted towards teaching of pre-clinical basic dental science subjects, which are followed by clinical component beginning in third year of BDS. At the end of each year, a comprehensive examination is taken for final assessment of the students. A minimum of one-year training in a recognized hospital setting is mandatory for registration of dental graduate as independent dental practitioner. $^{2}$ Majority of the time, this clinical training is based on rotational duties in oral surgery, prosthetic,

1. Assistant Professor \& MHPE-II Scholar, Department of Oral Biology \& Department of Medical Education, University of Health Sciences, Lahore.

2. Professor, Department of Medical education, University of Health Sciences, Lahore Corresponding author: "Dr. Sarah Ghafoor" < sarahghafoor@uhs.edu.pk > periodontology, orthodontics and restorative dentistry. ${ }^{2}$ Although, such rotations enable the beginner dentist to treat one specific dental problem at one given time but restricts the application of a holistic approach for comprehensively treating the dental patient.

\section{Competency-based Dental Education}

The type of training approach given to the graduate may depend on the type of the curriculum that is being taught to the students. Majority of curriculum taught in a dental school broadly fall into two main categories, prescriptive and outcome-based. ${ }^{3}$ In the former category, more focus is placed on teaching with little or no integration between subjects and across disciplines. This type of education is teachercentered and requires a large volume of factual knowledge and learning of certain taught traits. The universities in Pakistan are following a change to be in line with the global trends and integrating outcome-based curriculum in which goals of the educational experience are clearly defined and also means to achieve those goals are clearly implemented. Thus undergraduate dental education is now evolving from a discipline-focused and largely teacher-centered approach to an out-come based or competency-based education. ${ }^{1,4}$ This type of curriculum is broadly student-centered. It also 
allows vertical and horizontal integration and challenges students for critical thinking. ${ }^{3}$ As the competency-based education is based on identification of clearly defined learning outcomes, it mainly includes statements of competency, learning experience that supports such competencies and methods for assessment or measuring attainments of these competencies. $^{5}$

The introduction of a competency-based curriculum had started in the United States in 1993 when Chamber proposed that "Competencies are skills essential to begin practice of dentistry and allied dental practice. Competencies combine appropriate supporting knowledge and professional attitudes that are performed reliably in natural settings without assistance". 6 "Competence" can relate to professional performance or behavior that can include a wide range of personal attributes and qualities such as habitual and judicious use of communication, knowledge, technical skills, clinical reasoning, emotions, values, perceptiveness, creativity, receptivity, social skills and reflection in daily practice for the benefit of the individual and the community being served. It builds on the foundation of basic clinical skills, scientific knowledge, and moral development and involves cognitive function of acquiring and using knowledge to solve real-life problems. ${ }^{7}$ Competency can be a transition state toward expertise. It can also be defined as behaviors expected of a beginner and independent dental graduate that incorporates understanding, skills and values in an integrated response to the full range of circumstances that may be encountered in a general professional practice. ${ }^{8}$ Competency has been further defined by the working party of Competencies for Dental Licensure in Canada as "Competency is most often used to describe the skills, understanding and professional values of an individual ready for beginning independent dental or allied oral health care practice". 9

Since then, competency-based dental education is widely accepted in the profession and is believed to improve student's performance with

\section{Competence:}

Competence can be the professional performance or behavior that can include a wide range of personal attributes and qualities including knowledge, technical skills, clinical reasoning, values and reflection in daily practice. It builds on the foundation of basic clinical skills, scientific knowledge, and moral development and involves cognitive function of acquiring and using knowledge to solve real-life problems.

\section{Dental competencies:}

Skills needed to begin the practice of dentistry and allied dental profession. Competencies combine related knowledge and professional attitudes and are displayed reliably in natural settings without assistance.

\section{Gap Analysis:}

Gap analysis involves comparing actual performance with the intended competencies. This can be done through self-assessment, peer assessment or objective testing Beginner Dental Graduate:

A dentist who is in year one of clinical training after graduation

\section{Comprehensive Dental Care:}

Comprehensive dental care refers to in depth holistic dental care and management of a patient that not only involves a careful treatment planning and performing all the required dental procedures to improve oral health but if required, also a cooperation with physician to positively impact the overall health of an individual through treatment of oral disease. problem-solving, critical-assessment, discipline integration; and progressive autonomous selfassessment. ${ }^{10}$ Therefore, competency documents are constantly being developed by the educational experts and are used as framework to guide and encourage the development of curriculum and for assessment of students. ${ }^{11}$ They are also used in accreditation of a dental programs to ensure that a specific dental program has adequate depth and breadth of opportunities for students to achieve readiness for dental practice. ${ }^{12}$ The Association of Canadian Faculties of Dentistry (ACFD) has identified forty-seven competencies that act as a guide for the Canadian dental schools. ${ }^{12-14}$ Can-Meds is often used as frame work by many professional bodies to identify the core competencies in their graduates. ${ }^{15}$

The process of becoming a competent dental practitioner is not a simple on-going process but follows a continuum from novice to an expert stage depending upon both the individual and attaining mastery of the skill. ${ }^{1,6,16}$ For this reason, the educational principals of any dental school focus on facilitation of their graduate's primary objective which is the integration of their theoretical knowledge into the clinical dental 
practice while ensuring that the students have gained essential competencies in providing a holistic quality dental treatment. ${ }^{4,17-19}$ The dental literature has described competency-based dental education relative to pre-clinical and clinical dental practice ${ }^{5,20,21}$ and dental educators have developed these competencies as a framework to prepare and evaluate dental students in technical, diagnostic knowledge, skills and abilities. , $22,23^{2}$

It is however important to define, instruct and evaluate competency-based education in Pakistan so as to have a safe dental product. Fresh graduates are believed to be "competent" when they are able to function independently in a realistic practice environment. ${ }^{20}$ There is a difference that exists between perceived performance and the actual performance. The identification of this is the discrepancy or a "gap" analysis in which current behavior is compared with a "set" or an "accepted standard of practice" or intended competences. The exploration of factors or issues that create gap of practice in individual cases can also help identify the reason for such gaps. ${ }^{24,25}$

It has been suggested that newly graduated students are reluctant to openly admit a lack of confidence in skills that are essential for entry into a clinical dental practice. ${ }^{26}$ Therefore, it is necessary in for the undergraduate dental education to ensure that new graduated dentists are competent enough to be designated as safe independent practitioners, and are committed to continue to develop their professional knowledge, understanding and skills. ${ }^{1}$ Previous published studies highlight the importance of development and validation of a competency system for dental curriculum. The repeated iterations of goals, standard settings, design of experiences and appraisal is essential for transforming dental education institutes into true learning organizations. ${ }^{27,28}$ It has been shown that essential information leading to reforms in dental curriculum has been generated by surveying dentists regarding competencies in skills, knowledge and attitudes of the dental education program. ${ }^{29}$ Similarly, the University of Texas Health Sciences Center at San Antonio involved their faculty, students, alumni and outside consultants to re-evaluate the competencies of their program to ensure they are contemporary and methods to asses them are valid and reliable. ${ }^{30}$ Same has been achieved by assessing competencies for dental public health professionals and physical therapy specialists. ${ }^{31-33}$ It has been suggested that faculties of dentistry in Canada use the "competencies of beginner dentists" as a bench mark against which the dental curriculum offerings can be measured more appropriately. ${ }^{11}$

\section{Need for Competent Dental Graduate in Pakistan}

Dental education in Pakistan faces many challenges that may include issues related with the educational environment, type of curriculum taught and limited research resources.$^{34,35}$ There is a need to revisit the current curriculum design and educational strategies in line with the educational objectives. ${ }^{34}$ Researchers in Pakistan have proposed certain outcome competencies through brain storming and Delphi technique that (a) Pakistani graduate of dental profession should possess before entering into the community. These include thirty measureable outcomes that have been grouped under two broad categories of "clinical skills" and "professional behaviors". ${ }^{3}$ These competencies are based on themes including clinical competence, confidence and multidisciplinary approach, role in health service, treatment planning, attitude, ethical stance and legal responsibilities communication skills, information handling and teaching. It was believed that these themes covered all areas of knowledge, skills and attitude, thus the dental graduates are expected to be functional and competent within our community. ${ }^{36}$ It is very important to be clear about the qualities of our Pakistani dental product (i.e., the dentist); only it can be ensured that the our graduated product is a safe dental practitioner and is able to perform competently as a junior practitioner in our community. ${ }^{36}$

\section{Identification of Practice Gaps in Dental Education}

In order to evaluate the success of any dental education program, it is very important to ensure that the goals of the curriculum are met with the expected standards. For this reason, it is important that stakeholders such as alumni, academic staff, employers and ultimately patients provide a global perceptive regarding the entire curriculum. ${ }^{11}$ Through such perspectives, it has been found that majority of dental students desire a curriculum that has a focus on developing clinical experience with more time in clinical environment. ${ }^{37}$ For this reason, it has been suggested that the professional preparedness of the graduating students can reflect the quality of the dental program. The Association of Canadian Faculties of Dentistry (ACFD) competency document has identified forty-seven competencies that guide Canadian dental schools. These competencies were later validated for a beginner dentist through validity surveys involving recent graduates, licensed dentists, examiners and deans of dental schools in Canada. ${ }^{13}$ Recently, studies have been done to analyze the importance of competencies expected from graduated Canadian dentists from a student's perspective in order to identify essential gaps in Canadian dental education. ${ }^{12,38}$

The Gaps in dental education have been identified from perceptive of various sources such as students, alumni, faculty members, employers and patients. Alumni of the dental school can provide essential information regarding strengths and weaknesses of the curriculum that they have 
received. Extensive studies have explored graduated student's perspectives to investigate preparedness of graduating dentists for integration into professional practice. Exploration of student's perception regarding learning environment, knowledge, skills, confidence and practice management skills has generated valuable data regarding their well- or ill-preparedness and also provided a base-line for curriculum restructuring to prepare students before entering into a competitive dental work force. ${ }^{12,26,35,39-53}$ Such data from students also provides insights about graduating dental students and their experiences in dental school can help curriculum developer regarding newer trends in dental education, student's future goals and in comprehensive care curriculum. ${ }^{37,53-56}$ Similarly, assessment from the teachers regarding performance of their students is also a useful tool to evaluate the overall clinical skills expected from the graduated dentists. ${ }^{57-59}$ Standardized patients have been used to assess communication and clinical skills of the graduates. ${ }^{60}$ Employer's perceptions have also generated important data in assessing clinical competencies of the graduates in a real clinical setting. Such studies have identified low confidence in certain competencies that are expected in dental graduates thus generating valuable information for need of additional or prolong trainings at undergraduate level. ${ }^{61-63}$ It has been shown that although dental graduates perceived themselves excellent in certain competencies such as treatment planning, community-based skills, administrative and management skills, and professional development skills their employers felt opposite and expressed concern. Thus information generated from such investigation has led to suggestions regarding further reforms in the existing curriculum. ${ }^{63}$

\section{CONCLUSION}

The curriculum developers and policy makers involved in designing and implementing dental curricula across Pakistan need to devise strategies to formulate an outcomebased dental curriculum that clearly guides educational institutes regarding competences expected from beginner Pakistani dentists and should work on gathering data regarding perception of students, alumni, faculty members, clinical trainers, employers and patients regarding quality of our dental graduate working as an independent dental health care professional.

\section{ACKNOWLEDGMENTS}

We would like to thank all the staff of the Department of Medical Education, University of Health Sciences Lahore and Higher Education Commission of Pakistan (HEC) for providing access to the National e-Library.

\section{CONFLICT OF INTEREST}

None to declare

\section{REFERENCES}

1. Chuenjitwongsa S, Oliver R, Bullock A. Competence, competencybased education, and undergraduate dental education: a discussion paper. Eur J Dent Educ. 2016;22:3-10.

2. Shah MA, Darby M, Bauman D. Improving oral health in Pakistan using dental hygienists. Int J Dent Hyg. 2011;9:43-52.

https://doi.org/10.1111/j.1601-5037.2009.00434.x

3. Khan JS, Tabasum S, Mukhtar O, Iqbal M. Developing the Outcomes of a Baccalaureate of Dental Surgery Programme. J Ayub Med Coll Abbottabad. 2010;22:205-9.

4. Manogue M, McLoughlin J, Christersson C, Delap E, Lindh C, Schoonheim-Klein M, et al. Curriculum structure, content, learning and assessment in European undergraduate dental education-update 2010. Eur J Dent Educ. 2011;15:133-41.

https://doi.org/10.1111/j.1600-0579.2011.00699.x

5. Hagan BA. Tools for implementing a competency-based clinical curriculum: the dental school experience. J Vet Med Educ. 2008;35:369-74. https://doi.org/10.3138/jvme.35.3.369

6. Chambers DW. Toward a competency-based curriculum. J Dent Educ. 1993;57:790-

7. Epstein RM, Hundert EM. Defining and assessing professional competence. Jama. 2002;287:226-35.

https://doi.org/10.1001/jama.287.2.226

8. Chambers D. Competencies: a new view of becoming a dentist. J Dent Educ. 1994;58:342.

9. Boyd MA, Gerrow JD, Chambers DW, Henderson B. Competencies for dental licensure in Canada. J Dent Educ. 1996;60(10):842-6.

10. Yip H-K, Smales R. Review of competency-based education in dentistry. Br Dent J. 2000;189:324-6.

https://doi.org/10.1038/sj.bdj.4800758

11. Dagenais ME, Hawley D, Lund JP. Assessing the effectiveness of a new curriculum: Part I. J Dent Educ. 2003;67:47-54.

12. Whitney EM, Walton JN, Aleksejuniene J, Schönwetter DJ. Graduating Dental Students' Views of Competency Statements: Importance, Confidence, and Time Trends from 2008 to 2012. J Dent Educ. 2015;79:322-30.

13. Gerrow JD, Murphy HJ, Boyd MA. Competencies for the beginning dental practitioner in Canada: a validity survey. J Dent Educ. 2006;70:1076-80. 
14. Frank JR, Danoff D. The CanMEDS initiative: implementing an outcomes-based framework of physician competencies. Med Teach. 2007;29:642-7. https://doi.org/10.1080/01421590701746983

15. Frank J. The CanMEDS 2005 Physician Competency Framework. Ottawa, Ontario, Canada: Royal College of Physicians and Surgeons of Canada; 2005.

16. Chambers DW. Competency-based dental education in context. Eur J Dent Educ. 1998;2:8-13. https://doi.org/10.1111/j.1600-0579.1998.tb00029.x

17. Manogue M, Brown G. Managing the curriculum-for a change. Eur J Dent Educ. 2007;11:75-86. https://doi.org/10.1111/j.1600-0579.2007.00444.x

18. Albino JE, Young SK, Neumann LM, Kramer GA, Andrieu SC, Henson L, et al. Assessing dental students' competence: best practice recommendations in the performance assessment literature and investigation of current practices in predoctoral dental education. $\mathrm{J}$ Dent Educ. 2008;72:1405-35.

19. Willis DO. Using competencies to improve dental practice management education. J Dent Educ. 2009;73:1144-52.

20. Chambers DW, Gerrow JD. Manual for developing and formatting competency statements. J Dent Educ. 1994;58:361-66.

21. Shiloah J, Scarbecz M, Bland P, Hottel T. A comprehensive clinical competency-based assessment in periodontics. Eur J Dent Educ. 2016.

22. O'Neill PA. Competencies: meaning for the overall and clinical dental curriculum. J Dent Educ. 1994;58:349-50.

23. Chambers DW, Glassman P. A primer on competency-based evaluation. J Dent Educ. 1997;6:651-66.

24. Norman GR, Shannon SI, Marrin ML. The need for needs assessment in continuing medical education. Bmj. 2004;328(7446):9991001.

https://doi.org/10.1136/bmj.328.7446.999

25. Grant J. Learning needs assessment: assessing the need. Bmj. 2002;324(7330):156-9.

https://doi.org/10.1136/bmj.324.7330.156

26. Greenwood LF, Townsend GC, Wetherell JD, Mullins GA. Selfperceived competency at graduation: a comparison of dental graduates from the Adelaide PBL curriculum and the Toronto traditional curriculum. Eur J Dent Educ. 1999;3:153-8.

https://doi.org/10.1111/j.1600-0579.1999.tb00085.x

27. Gerrow JD, Chambers DW, Henderson BJ, Boyd MA. Competencies for a beginning dental practitioner in Canada. J Can Dent Assoc. 1998;64:94-7.

28. Glassman P, Chambers D. Developing competency systems: a never-ending story. J Dent Educ. 1998;62:173-82.
29. Shugars DA, Bader JD, O'Neil E. Attitudes of dentists toward emerging competencies for health care practitioners. J Dent Educ. 1992;56:640-5.

30. Glass B, Dodge W, MacDougall M, Kalkwarf K. The UTHSCSA Dental School in the new millennium. Tex Dent J. 2000;117:12-20.

31. Weintraub JA. The development of competencies for specialists in dental public health. J Public Health Dent. 1998;58(s1):114-8. https://doi.org/10.1111/j.1752-7325.1998.tb02539.x

32. Zachazewski JE, Felder CR, Knortz K, Thein L, Quillen WS. Competency revalidation study: a description of advanced clinical practice in sports physical therapy. J Orthop Sports Phys Ther. 1994;20:110-24.

https://doi.org/10.2519/jospt.1994.20.2.110

33. Gaunkar RB, Basavarajappa P, Raheel SA, Kujan OB. Perception of Dental Public Health Competency among recent graduates. J Int Soc Prev Community Dent. 2016;6(Suppl 2):S137. https://doi.org/10.4103/2231-0762.189741

34. Amin M, Ahmed B. Dental education in Pakistan: Current trends and practices. JCPSP. 2010;20:497-8.

35. Ali K, Raja M, Watson G, Coombes L, Heffernan E. The dental school learning milieu: students' perceptions at five academic dental institutions in Pakistan. J Dent Educ. 2012;76:487-94.

36. Khan JS, Mukhtar O, Tabbasum S. Perceived variations in dental graduate competency outcomes based on demographic variables. Pak Oral Dent J. 2012;32(1).

37. Henzi D, Davis E, Jasinevicius R, Hendricson W, Cintron L, Isaacs M. Appraisal of the dental school learning environment: the students' view. J Dent Educ. 2005;69:1137-47.

38. Schönwetter D, Law D, Mazurat R, Sileikyte R, Nazarko O. Assessing graduating dental students' competencies: the impact of classroom, clinic and externships learning experiences. Eur J Dent Educ. 2011;15:142-52

https://doi.org/10.1111/j.1600-0579.2010.00648.x

39. Lévy G, d'Ivernois JF, Brun D, Gagnayre R. A French dental school programme appraisal by alumni of 5-9 years standing. Eur J Dent Educ. 1997;1:70-7.

https://doi.org/10.1111/j.1600-0579.1997.tb00015.x

40. Greenwood L, Lewis D, Burgess R. How competent do our graduates feel? J Dent Educ. 1998;62:307-13.

41. Murray FJ, Blinkhorn AS, Bulman J. An assessment of the views held by recent graduates on their undergraduate course. Eur J Dent Educ. 1999;3:3-9.

https://doi.org/10.1111/j.1600-0579.1999.tb00059.x

42. Ryding HA, Murphy H. Assessing outcomes of curricular change: a view from program graduates. J Dent Educ. 2001;65:422-26.

43. McGrath C, Corbet EF. Do dental graduates of the University of 
Hong Kong (1997-2001) perceive themselves prepared for dental practice? Hong Kong Dent J. 2005;2:85-91.

44. Arena G, Kruger E, Holley D, Millar S, Tennant M. Western Australian dental graduates' perception of preparedness to practice: A five-year follow-up. J Dent Educ. 2007;71:1217-22.

45. Rafeek RN, Marchan SM, Naidu RS, Carrotte PV. Perceived competency at graduation among dental alumni of the University of the West Indies. J Dent Educ. 2004;68:81-8.

46. Nicolas E, Baptiste M, Roger-Leroi V. Clermont-Ferrand dental school'curriculum: an appraisal by last-year students and graduates. Eur J Dent Educ. 2009;13:93-9.

https://doi.org/10.1111/j.1600-0579.2008.00547.x

47. Manakil J, Rihani S, George R. Preparedness and practice management skills of graduating dental students entering the work force. Educ Res Int. 2015.

https://doi.org/10.1155/2015/976124

48. Yiu C, McGrath C, Bridges S, Corbet E, Botelho M, Dyson J, et al. Self-perceived preparedness for dental practice amongst graduates of The University of Hong Kong's integrated PBL dental curriculum. Eur J Dent Educ. 2012;16:e96-e105. https://doi.org/10.1111/j.1600-0579.2011.00681.x

49. Houlberg BJ. Dental residents' perceptions of practice and patient management training during postgraduate education. J Dent Educ. 2008;72:643-52.

50. Nadershahi N, Nielsen D. Educating the practice-ready dentist. J Calif Dent Assoc. 2005;33:801-4.

51. Cardall WR, Rowan RC, Bay C. Dental education from the students' perspective: curriculum and climate. J Dent Educ. 2008;72:6009.

52. Kossioni A, Varela R, Ekonomu I, Lyrakos G, Dimoliatis I. Students' perceptions of the educational environment in a Greek Dental School, as measured by DREEM. Eur J Dent Educ. 2012;16:e73-e8. https://doi.org/10.1111/j.1600-0579.2011.00678.x

53. Gerbert B, Badner V, Maguire B, Martinoff J, Wycoff S, Crawford W. Recent graduates' evaluation of their dental school education. J Dent Educ. 1987;51:697-700.
54. Baharvand M, Moghaddam EJ, Pouretemad H, Alavi K. Attitudes of Iranian dental students toward their future careers: an exploratory study. J Dent Educ. 2011;75:1489-95.

55. Garrison GE, Lucas-Perry E, McAllister DE, Anderson E, Valachovic RW. Annual ADEA survey of dental school seniors: 2013 graduating class. J Dent Educ. 2014;78:1214-36.

56. Holmes D, Diaz-Arnold A, Williams V. Alumni self-perception of competence at time of dental school graduation. J Dent Educ. 1997;61:465-72.

57. Lam T, Khoo U, Chan Y, Cheng Y, Lam K. The first batch of graduates of a new medical curriculum in Asia: how their teachers see them. Med Educ. 2004;38:980-86.

https://doi.org/10.1111/j.1365-2929.2004.01910.x

58. Stacey M, Morgan M, Wright C. The effect of clinical targets on productivity and perceptions of clinical competency. J Dent Educ. 1998;62:409-14.

59. Khan I, Fareed A. Perceptions of students and faculty about conventional learning and community-oriented medical education. JCPSP. 2003;13:82-5.

60. Johnson J, Kopp K. Effectiveness of standardized patient instruction. J Dent Educ. 1996;60:262-66.

61. Bartlett D, Coward P, Wilson R, Goodsman D, Darby J. Vocational training: Experiences and perceptions of vocational training reported by the 1999 cohort of vocational dental practitioners and their trainers in England and Wales. Br Dent J. 2001;191:265-70.

https://doi.org/10.1038/sj.bdj.4801159

62. Patel J, Fox K, Grieveson B, Youngson CC. Undergraduate training as preparation for vocational training in England: a survey of vocational dental practitioners' and their trainers' views. Br Dent J. 2006;201:915.

https://doi.org/10.1038/sj.bdj.4814067

63. Razak IA, Rj RL, Jaafar N, Mi AH, Ab Murat N. Assessing the competency of University of Malaya dental graduates: employers' and graduates' perceptions. J Dent Educ. 2008;72:364-9. 